\title{
Association of Salivary Cortisol Circadian Pattern With Cynical Hostility: Multi-Ethnic Study of Atherosclerosis
}

\author{
Nalini Ranjit, PhD, Ana V. Diez-Roux, MD, PhD, Brisa Sanchez, PhD, Teresa Seeman, PhD, \\ Steven Shea, MD, MS, Sandi Shrager, MSW, and Karol Watson, MD, PhD
}

\begin{abstract}
Objective: To determine if cynical hostility is associated with alterations in diurnal profiles of cortisol. Hostility has been linked to cardiovascular disease but the biological mechanisms mediating this association remain unknown. Methods: Up to 18 measures of salivary cortisol taken over 3 days were obtained from each of 936 participants in the Multi-Ethnic Study of Atherosclerosis (MESA). Cynical hostility was measured using an eight-item subscale of the Cook-Medley Hostility Scale. Cortisol profiles were modeled using regression spline models that incorporated random parameters for subject-specific effects. Models were adjusted for race, sex, age, socioeconomic position, and lifestyle factors. The association of cynical hostility with key features of the cortisol diurnal profile, both in the full sample and important subsamples, was examined. Results: Waking cortisol levels as well as the extent of the morning surge in cortisol levels did not differ significantly across tertiles of cynical hostility. Respondents in the lowest tertile of cynical hostility experienced a $22 \%$ sharper decline in salivary cortisol (age- and sex-adjusted slope of $-0.49 \mu \mathrm{g} / \mathrm{dL}$ per hour) than respondents in the highest tertile $(-0.40 \mu \mathrm{g} / \mathrm{dL}$ per hour, $p$ for difference $=.0004)$. Intertertile differences in these parameters remained unaltered after further adjustment for potential confounders. This pattern of differences in cortisol diurnal profile tended to be related in a dose-response way to level of cynical hostility, and persisted in stratified analyses. Conclusions: Cynical hostility is associated with the declining phase of the awakening cortisol response. The implications of this for cardiovascular and other health outcomes remain to be determined. Key words: cortisol rhythms, cynical hostility, regression splines, random effects, cortisol awakening response.
\end{abstract}

MESA = Multi-Ethnic Study of Atherosclerosis; BMI = body mass index; $\mathbf{C A R}=$ cortisol awakening response; $\mathbf{S E P}=$ socioeconomic position; CHD = coronary heart disease; CVD = cardiovascular disease.

\section{INTRODUCTION}

$\mathrm{T}$ here is growing interest in understanding the biological pathways underlying the long-observed associations between adverse psychosocial traits, such as depression and hostility, and cardiovascular outcomes (1-5). One pathway of interest relates to the role of psychosocial traits in modulating the release of cortisol $(6,7)$. Cortisol has many physiologic effects $(8,9)$, and glucocorticoid receptors are found in the cells of almost all tissues in the body. A large number of cardiovascular, metabolic, immunologic, and homeostatic functions are regulated by cortisol. For example, excessive glucocorticoid action is believed to play a role in the development of insulin resistance $(10,11)$, and is associated with other cardiovascular risk factors, such as central obesity (12) and hypertension (13). Prolonged exposure to cortisol has been postulated to result in a reduction of cortisol's ability to inhibit the action of proinflammatory cytokines $(14,15)$. In

From the Michael \& Susan Dell Center for Advancement of Healthy Living (N.R.), University of Texas School of Public Health, Austin Regional Campus, Texas; Center for Integrative Approaches to Health Disparities (A.V.D.-R.), Department of Epidemiology, University of Michigan, Ann Arbor, Michigan; Department of Biostatistics (B.S.), School of Public Health, University of Michigan, Ann Arbor, Michigan; Department of Medicine (T.S.), University of California, Los Angeles, Los Angeles, California; Departments of Medicine and Epidemiology (S.S.), Columbia University College of Physicians and Surgeons and Mailman School of Public Health, New York, New York; Collaborative Health Studies Coordinating Center (S.S.), University of Washington, Seattle, Washington; Division of Cardiology (K.W.), Geffen School of Medicine, University of California, Los Angeles, Los Angeles, California.

Disclosure: There is no conflict of interest.

Received for publication September 5, 2008; revision received April 16, 2009.

This work was supported by Grant R01 HL076831 (PI: Ana V. Diez-Roux). MESA was supported by Contracts N01-HC-95159 through N01-HC-95165 and N01-HC-95169 from the National Heart, Lung, and Blood Institute.

DOI: 10.1097/PSY.0b013e3181ad23e7 view of this diverse array of effects, it is possible that cortisol is part of the biologic pathway linking psychosocial factors and cardiovascular outcomes.

Hostility and depression are two of the psychosocial traits linked most consistently to cardiovascular risk factors and outcomes. Several recent studies documented alterations in the diurnal rhythm of cortisol in the presence of major depression (16-19). In contrast, evidence relating dysregulation of cortisol rhythms to hostility, another well-established psychosocial risk factor for cardiovascular disease (CVD) (20-24), is limited and inconsistent. One small study $(n=39)$ found daytime elevations of urinary cortisol among men with high hostility levels relative to men with low hostility, with no differences seen in awakening or evening cortisol (25). In a larger study, cynical hostility was associated with flattening of cortisol rhythms among 257 Swedish adults aged 30 to 64 years (26), but the study collected only three cortisol measures over the course of 1 day, which may have limited the ability to detect alterations of the diurnal rhythm. Another study of 109 adults with up to six measures a day collected over 2 days failed to detect an association between hostility and overall shape of cortisol profile (27).

We examined whether cortisol rhythms were associated with cynical hostility in a large population sample with detailed assessments of cortisol over several days, allowing the examination of multiple features of circadian rhythms of cortisol. Specifically, we hypothesized that elevated hostility levels would be associated with differences in one or more features of the daily cortisol profile, resulting in greater exposure to cortisol for more hostile persons compared with less hostile persons. Data for the study were obtained from a subsample of US adults participating in the Multi-Ethnic Study of Atherosclerosis (MESA) cohort.

\section{METHODS}

\section{Participants}

MESA is a longitudinal multisite observational study supported by the National Heart, Lung and Blood Institute with the goal of identifying risk factors for subclinical atherosclerosis. Details of the study design have been 
published elsewhere (28). Between July 2004 and November 2006, in conjunction with the second and third follow-up examinations of the full MESA sample, a subsample of 1002 participants at the New York and Los Angeles sites of MESA were recruited for a substudy of biological stress markers (the MESA Stress Study), which included repeat assessments of salivary cortisol. At each participating site, all white, Hispanic, and African-American participants were invited to participate in the MESA Stress Study in the order in which they attended the follow-up examination. Enrollment continued until approximately 500 participants were enrolled at each site. The study was approved by Institutional Review Boards at all participating institutions. All subjects gave their written informed consent.

\section{Cortisol Measurement}

Each MESA Stress Study participant was instructed, by trained staff, to collect six salivary samples a day (directly on waking; 30 minutes after waking; $10 \mathrm{AM}$; $12 \mathrm{PM}$ or before lunch, whichever was earlier; $6 \mathrm{PM}$ or before dinner whichever was earlier; and at bedtime). This daily collection protocol was repeated on each of 3 successive weekdays; thus, each participant provided up to 18 cortisol measures.

Saliva samples were collected, using cotton swabs and stored at $-20^{\circ} \mathrm{C}$ until analysis. Before biochemical analysis, samples were thawed and centrifuged at $3000 \mathrm{rpm}$ for 3 minutes to obtain clear saliva with low viscosity. Cortisol levels were determined, employing a commercially available chemiluminescence assay with high sensitivity of $0.16 \mathrm{ng} / \mathrm{mL}$ (IBL Hamburg, Hamburg, Germany). Intra- and interassay coefficients of variation are $<8 \%$ (29). Cortisol values were $\log$ transformed for statistical analyses.

Participants recorded collection time on special cards; in addition, a time-tracking device (Track Caps, Medication Events Monitoring System, Aprex, Union City, California) automatically registered the time at which cotton swabs were extracted to collect each sample. Participants were told of this time-tracking device. In analyses, the time recorded on the Track Caps was used as the time of data collection. The first sample time was used as the wake-up time, as participants were instructed to take the first sample on waking. When the first sample was not collected ( $<2 \%$ of days), waking time recorded on the daily questionnaire was used instead. Observations without a first sample time or a reported waking time $(<0.2 \%$ of observations) were dropped from analysis.

\section{Cynical Hostility}

Cynical hostility, derived from an eight-item subscale of the full CookMedley Hostility Scale, was the key hostility measure examined. Cynical hostility, a key component of hostility (30), has been linked to inflammation, subclinical atherosclerosis, and cardiovascular mortality in earlier studies (31-35). Both the continuous version of the scale as well as categories based on tertiles of the observed distribution in the sample were examined. The continuous version was standardized so that each unit on the transformed scale corresponded to 1 standard deviation on the original scale.

\section{Potential Confounders and Mediators}

Information on factors that may confound or mediate the association between hostility and cortisol levels (sociodemographic factors, smoking, and body mass index) was collected through questionnaires and direct measurement. Race/ethnicity was classified as non-Hispanic white, non-Hispanic African-American (Black), and Hispanic. Participants selected their total combined family income from a total of 13 categories ranging from $<\$ 5000$ to $>\$ 100,000$ (USD), and their highest level of education from eight categories ranging from no schooling to graduate or professional education. Continuous versions of income and education were constructed, using midpoints of these categorical responses. Smoking was categorized into current, past, or never use. Body mass index (BMI) was calculated as weight in $\mathrm{kg}$ divided by height in meters squared and was modeled both as a continuous variable as well as in standard categories (normal, overweight (BMI between 25 and 29.9), and obese (BMI of $>30$ )). Participants who reported use of oral or inhaled steroids (about $3 \%$ of the sample) were excluded from the analysis. Measures of cynical hostility and covariates were obtained from either the baseline or the first follow-up examination of MESA.

\section{Statistical Analyses}

Two characteristics of the collected cortisol samples dictated the logic of the statistical methods employed here. First, cortisol shows a well-documented circadian pattern typified by a rapid early morning peak within 30 to 45 minutes after waking, followed by a decline over most of the day (36). To capture all the relevant inflections of this complex circadian rhythm, we modeled daily cortisol values as a function of time since wake up, using linear regression splines with "knots" located to capture the ascending and descending phases of the cortisol awakening response (CAR), and the slower decline over the course of the day. Knots were located at 30 and 120 minutes after wake up. The location of the knots was predetermined from visual examination of smoothed plots of cortisol data by time since wake up, and confirmed in post hoc analyses by comparing the fit of models with different number and location of knots. The presence of these knots allows the relationship between time after wake up and cortisol levels (i.e., the slopes associated with time) to vary over the day.

The model fitted allows estimation of four parameters of interest: the intercept (or mean cortisol value at time 0 or at wake up), the change in cortisol between wake up and 30 minutes after wake up (or the rapidly ascending slope of the CAR, which we refer to as the Phase 1 slope); the change in cortisol between 30 and 120 minutes post wake up (or the rapidly descending slope of the CAR, which we refer to as the Phase 2 slope); and the change in cortisol between 120 minutes after wake up and bedtime, which we refer to as the Phase 3 slope. In earlier work, we have characterized successfully the diurnal rhythm of cortisol, using these four parameters $(37,38)$. By including covariates in the model as main effects and in interaction with the different slope parameters, we are able to estimate how these parameters vary as a function of covariates, such as cynical distrust, after adjusting for other risk factors.

A second consideration in choice of statistical analysis is the need to account for correlations between repeat measures on a given individual and to allow for varying numbers of repeat measures within a person as well as variations in the times of sample collection. To account for correlations, we included a random intercept for each person as well as random coefficients for the slopes. These models, which are also referred to as multilevel or mixed models (39), allow for differences in the number of samples per person as well as for differences in the timing of data collection; the variability in collection times is exploited by the method to provide more robust estimates (40). For maximum flexibility, no structure was imposed on the random-effects covariance matrix. To protect against misspecification of the residual error variancecovariance matrix, the robust, asymptotically consistent sandwich estimator (41) was used to obtain standard errors and test-statistics for fixed-effect parameters. SAS (v 9.1.2) (SAS Institute, Cary, North Carolina) was used to estimate these parameters.

To examine associations of cynical hostility with cortisol rhythm, the trait measure was allowed to alter the intercept as well as the slopes of Phase 1, Phase 2, and Phase 3, modeled as linear splines. This was done by including a main effect (to raise or lower the intercept) and an interaction term between cynical hostility and each of the three slope terms. To estimate associations of cynical hostility with portions of the curve after control for confounders and mediators, all potential confounders (including wake-up time, day of collection, race/ethnicity, income, education, smoking, and BMI) were included in the model as main effects and in interaction with each of the slope terms.

In stratified analyses, we also examined whether any associations of cynical hostility with features of the cortisol profiles varied by age, race/ ethnicity, or sex. To maximize power, cynical hostility was modeled as a continuous variable in these analyses. The $p$ values for differences across strata were obtained from models that included three-way interactions between the corresponding stratifying variable, cynical hostility, and the slope term of interest. Finally, sensitivity analyses examined the extent to which these findings were robust to different ways of assessing wake-up time, to different specifications of the model (i.e., minor changes in the location of the knots), and to the exclusion of samples collected $>15$ hours after wake up. 
TABLE 1. Means and Percent Distributions of Respondent Characteristics, Full Sample and by Cynical Hostility Tertiles, the Multi-Ethnic Study of Atherosclerosis (MESA) Stress Study, 2004-2006

\begin{tabular}{|c|c|c|c|c|c|}
\hline & $\begin{array}{l}\text { Full Sample } \\
\qquad(n=936)\end{array}$ & $\begin{array}{l}\text { Lowest Tertile of } \\
\text { Cynical Hostility } \\
\qquad(n=376)\end{array}$ & $\begin{array}{l}\text { Middle Tertile } \\
\text { of Cynical Hostility } \\
(n=242)\end{array}$ & $\begin{array}{l}\text { Highest Tertile } \\
\text { of Cynical Hostility } \\
(n=318)\end{array}$ & $p^{a}$ \\
\hline Range and mean (SD) of cynical & $0-8$ & $0-2$ & $3-4$ & $5-8$ & \\
\hline hostility scores & $3.3(2.5)$ & $0.81(0.8)$ & $3.5(0.5)$ & $6.2(1.1)$ & \\
\hline \multicolumn{6}{|l|}{$\begin{array}{c}\text { Demographic, socioeconomic } \\
\text { and lifestyle variables }\end{array}$} \\
\hline Mean age (years) & 61.4 & 61.8 & 60.6 & 61.7 & .28 \\
\hline \multicolumn{6}{|l|}{ Sex (\% distribution) } \\
\hline Male & 48 & 44.4 & 48.8 & 51.9 & \\
\hline Female & 52 & 55.6 & 51.2 & 48.1 & .14 \\
\hline \multicolumn{6}{|l|}{ Race/ethnicity (\% distribution) } \\
\hline White & 19.2 & 33.5 & 14.5 & 6.6 & \\
\hline Black & 28.3 & 27.9 & 33.5 & 23.9 & \\
\hline Hispanic & 52.5 & 38.6 & 52.1 & 69.5 & $<.0001$ \\
\hline Mean body mass index & 29.0 & 28.5 & 29.1 & 29.4 & .08 \\
\hline \multicolumn{6}{|l|}{ Smoking (\%) } \\
\hline Never smoked & 53 & 55.9 & 47.1 & 52.2 & \\
\hline Former smokers & 36 & 35.6 & 39.7 & 33.3 & \\
\hline Current smokers & 11 & 8.5 & 13.2 & 14.5 & .05 \\
\hline Mean income (in thousands USD) & 41.1 & 52.1 & 38.8 & 30.0 & $<.0001$ \\
\hline Mean years of education & 12.3 & 14.3 & 12.7 & 9.7 & $<.0001$ \\
\hline \multicolumn{6}{|l|}{ Characteristics of cortisol measures } \\
\hline Mean wake-up time & $6: 40 \mathrm{AM}$ & $6: 42$ AM & $6: 35 \mathrm{AM}$ & $6: 38$ AM & $<.0001$ \\
\hline Mean (SD) number of cortisol measures & $17.92(0.74)$ & $17.96(0.50)$ & $17.93(0.75)$ & $17.89(0.93)$ & $<.0001$ \\
\hline
\end{tabular}

${ }^{a}$ Tests for difference across levels of cynical hostility are obtained using F statistics (for continuous variables) and $\chi^{2}$ ratios for categorical variables. $\mathrm{SD}=$ standard deviation.

\section{RESULTS}

The cortisol data used for this analysis included 16,728 observations obtained from 936 respondents with available data on cynical hostility, collected over a total of 2788 days. Correlations of mean cortisol level across days of collection for each individual varied from 0.65 to 0.72 , suggesting low-tomoderate intraindividual variability. Demographic characteristics and cortisol sample characteristics by tertiles of cynical hostility are shown in Table 1. Age and sex distributions were approximately similar across tertiles of cynical hostility, although there are higher proportions of women in the lowest cynical hostility category and higher proportions of men in the highest cynical hostility category. Whites were overrepresented in the lowest cynical hostility category, whereas Hispanics were overrepresented in the highest cynical hostility category. Greater cynical hostility was associated with higher probability of being a current smoker, and slightly higher BMI. Socioeconomic position (SEP), as indicated by annual income and years of education, decreased across increasing levels of cynical hostility. Higher cynical hostility was associated with slightly earlier wake-up times and slightly lower numbers of cortisol measures, although differences were very small.

Figure 1 shows log cortisol values in the sample over the course of the day, characterized as hours from the time of waking for each respondent. A distinct peak is observed at 30 minutes past waking (during Phase 1), after which cortisol levels decrease rapidly until about 120 minutes past waking (Phase 2), and then more gradually over the course of the day

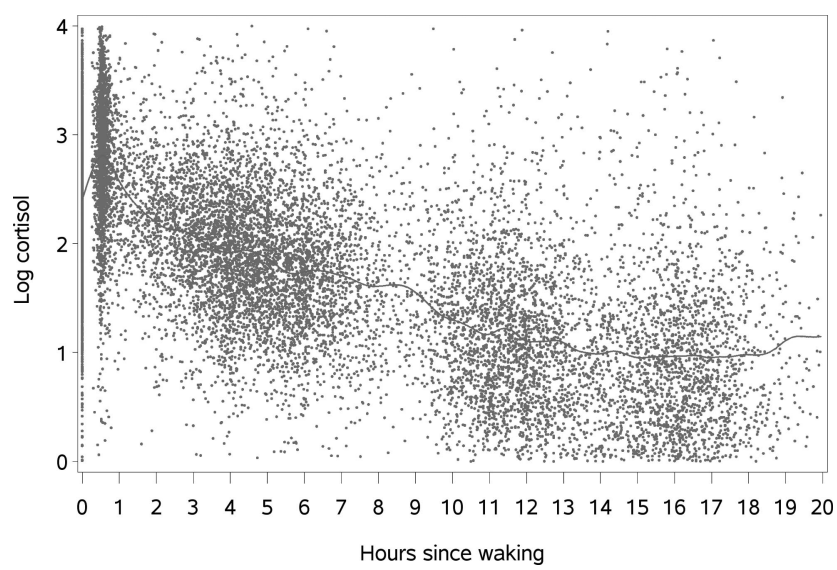

Figure 1. Diurnal pattern of salivary cortisol, the Multi-Ethnic Study of Atherosclerosis (MESA) Stress Study, 2004 to 2006. $n=936$.

(Phase 3). Knot locations were assigned accordingly to the 30and 120-minute time points, respectively, allowing specification of regression spline models with separate slopes for 0 to 30 minutes, 30 to 120 minutes, and 120 minutes to the end of the day.

Estimated values of log cortisol at the wake-up time and slopes (mean differences in log cortisol per hour) for each of the three phases for each level of cynical hostility are shown in Table 2. Model 1, the basic model, adjusts for age, sex, day of collection, and wake-up time. Model 2 adds race/ethnicity, and Model 3 adds race/ethnicity and SEP to the basic model. Model 4, the most comprehensive model, adjusts for lifestyle 
TABLE 2. Adjusted Log Cortisol Values at Wake Up and Mean Differences in Log Cortisol per Hour for Different Portions of the Cortisol Curve by Tertiles of Cynical Hostility, the Multi-Ethnic Study of Atherosclerosis (MESA) Stress Study, 2004-2006

\begin{tabular}{|c|c|c|c|c|}
\hline & $\begin{array}{c}\text { Model } 1 \\
\text { Estimate (SE) }\end{array}$ & $\begin{array}{c}\text { Model } 2 \\
\text { Estimate (SE) }\end{array}$ & $\begin{array}{c}\text { Model } 3 \\
\text { Estimate (SE) }\end{array}$ & $\begin{array}{c}\text { Model } 4 \\
\text { Estimate (SE) }\end{array}$ \\
\hline Wake-up value (top tertile of cynical hostility) & $2.36(0.03)$ & $2.39(0.03)$ & $2.38(0.04)$ & $2.4(0.04)$ \\
\hline Wake-up value (middle tertile of cynical hostility) & $2.41(0.04)$ & $2.42(0.04)$ & $2.41(0.03)$ & $2.43(0.04)$ \\
\hline Wake-up value (lowest tertile of cynical hostility) & $2.44(0.03)$ & $2.41(0.03)$ & $2.38(0.03)$ & $2.39(0.04)$ \\
\hline Intercept difference for intertertile difference in cynical hostility & $-0.08(0.04)$ & $-0.02(0.05)$ & $0(0.05)$ & $0(0.05)$ \\
\hline$p$ for intertertile difference & .08 & .66 & .97 & .93 \\
\hline Phase 1 slope* (top tertile of cynical hostility) & $1.96(0.26)$ & $2.00(0.26)$ & $2.03(0.27)$ & $1.8(0.34)$ \\
\hline Phase 1 slope (middle tertile of cynical hostility) & $2.04(0.26)$ & $2.07(0.26)$ & $2.09(0.28)$ & $1.87(0.34)$ \\
\hline Phase 1 slope lowest tertile of cynical hostility) & $2.04(0.25)$ & $2.06(0.25)$ & $2.09(0.28)$ & $1.87(0.34)$ \\
\hline Phase1 slope difference for intertertile difference in cynical hostility & $-0.09(0.07)$ & $-0.06(0.08)$ & $-0.06(0.08)$ & $-0.07(0.08)$ \\
\hline$p$ for intertertile difference & .25 & .40 & .46 & .40 \\
\hline Phase 2 slope* (top tertile of cynical hostility) & $-0.40(0.09)$ & $-0.45(0.09)$ & $-0.39(0.09)$ & $-0.57(0.11)$ \\
\hline Phase 2 slope (middle tertile of cynical hostility) & $-0.45(0.08)$ & $-0.49(0.09)$ & $-0.43(0.09)$ & $-0.61(0.11)$ \\
\hline Phase 2 slope lowest tertile of cynical hostility) & $-0.49(0.09)$ & $-0.51(0.09)$ & $-0.45(0.09)$ & $-0.63(0.11)$ \\
\hline Phase 2 slope difference for intertertile difference in cynical hostility & $0.09(0.02)$ & $0.06(0.03)$ & $0.06(0.03)$ & $0.06(0.03)$ \\
\hline$p$ for intertertile difference & .0004 & .0136 & .0496 & .0461 \\
\hline Phase 3 slope* (top tertile of cynical hostility) $^{*}$ & $-0.14(0.01)$ & $-0.13(0.01)$ & $-0.13(0.02)$ & $-0.13(0.02)$ \\
\hline Phase 3 slope (middle tertile of cynical hostility) & $-0.13(0.01)$ & $-0.13(0.01)$ & $-0.12(0.02)$ & $-0.13(0.02)$ \\
\hline Phase 3 slope lowest tertile of cynical hostility) & $-0.13(0.01)$ & $-0.13(0.01)$ & $-0.12(0.02)$ & $-0.13(0.02)$ \\
\hline Phase 3 slope difference for intertertile difference in cynical hostility & $-0.01(0)$ & $0(0)$ & $0(0)$ & $0(0)$ \\
\hline$p$ for intertertile difference & .07 & .63 & .76 & .69 \\
\hline
\end{tabular}

All models adjust for day of collection and wakeup time; in addition, models include other adjustment variables as follows: Model 1: age + sex; Model 2: Model 1 + race/ethnicity; Model 3: Model 2 + socioeconomic position; Model 4: Model 3 + BMI + smoking.

Estimates are computed at the median or mean level of all covariates.

*Phases 1, 2, and 3 correspond to time periods 0 to $30 \mathrm{mins}, 30$ to $120 \mathrm{mins}$, and $>120$ mins past waking.

$\mathrm{SE}=$ standard error; $\mathrm{BMI}=$ body mass index.

factors (BMI and smoking) as well as age, sex, race/ethnicity, and SEP. All adjustment variables are included as main effects as well as in interaction with the slopes of each phase.

In all models, the slopes of both the ascending and descending limbs of the CAR were attenuated among respondents in the top tertile of cynical hostility, relative to the lowest tertile. In the case of Phase 2, the rapidly declining phase, the intertertile difference in slope was statistically significant across all models, showing little change in magnitude after adjustment for multiple factors. Across models, the Phase 2 slope was between $10 \%$ to $18 \%$ steeper in the lowest versus the highest tertile of hostility. Phase 1 patterns suggested a threshold effect between the bottom and middle tertiles (3\% to 5\% difference between the slopes of the top and bottom tertile) but differences were not statistically significant. No consistent differences across cynical hostility tertiles were seen in either the intercept (waking level) or in the slope of Phase 3.

Table 3 shows differences in each of the components of the cortisol profile associated with a 1-standard deviation increase in the cynical hostility score, for different age, sex, race/ ethnicity, and socioeconomic strata. In these analyses, a negative value for the Phase 1 slope and a positive value for the Phase 2 slope indicate slope attenuation of the ascending and descending limbs of the CAR with increases in cynical hostility. A positive value for the intercept indicates a higher waking level with cynical hostility, whereas a positive value for the Phase 3 slope implies that higher cynical hostility levels are associated with slower declines over most of the day after the CAR. Slight attenuation of the Phase 1 increase and a larger attenuation of the Phase 2 decrease with increasing cynical hostility are seen in most strata. In general, there was no clear evidence of differences in associations of cynical hostility with cortisol profiles across the different strata. Attenuation of the Phase 2 decline is significantly larger among 65 - to 84-year-olds compared with persons $<65$ years, and significantly smaller among Hispanics relative to whites and African-Americans, but in all strata, the slope for Phase 2 is flattened at higher levels of cynical hostility. In addition, there is some evidence of lower waking levels of cortisol and an attenuated Phase 1 slope with increased cynical hostility in blacks and Hispanics. Although statistical significance is harder to attain in these models both because of the reduced sample sizes, these findings seem consistent across strata.

Sensitivity analyses (not shown) examined the extent to which these findings were robust in subsets of the analysis sample, including participants with a wake-up time before 4 AM, those awake for $<12$ hours, and for each day of collection. For the most part, attenuation of Phase 1 and Phase 2 slopes at higher levels of cynical hostility was evident in each of these subgroups. Furthermore, this pattern persisted when we dropped observations collected $>15$ hours after wake-up as well as when we anchored all cortisol collection times to reported wake-up time rather than to time of first cortisol collection. 
TABLE 3. Mean Differences in Wake-Up Level of Log Cortisol and in Change in Cortisol per Hour for Different Portions of the Cortisol Curve Associated With a 1-SD Increase in Cynical Hostility Score, for Different Covariate Strata, the Multi-Ethnic Study of Atherosclerosis (MESA) Stress Study, 2004 to 2006

\begin{tabular}{|c|c|c|c|c|}
\hline & Mean at Wake-Up (SE) & Phase 1 Slope $^{a}(\mathrm{SE})$ & Phase 2 Slope (SE) & Phase 3 Slope (SE) \\
\hline \multicolumn{5}{|l|}{ Age (years) } \\
\hline $45-64$ & $-0.033(0.022)$ & $0.011(0.039)$ & $0.02(0.014)$ & $0.002(0.002)$ \\
\hline $65-84$ & $0.01(0.028)$ & $-0.089(0.046)$ & $0.036(0.013)$ & $-0.004(0.003)$ \\
\hline$p$ for difference across strata & .69 & .22 & .0104 & .98 \\
\hline \multicolumn{5}{|l|}{ Gender } \\
\hline Women & $-0.018(0.025)$ & $-0.022(0.045)$ & $0.017(0.016)$ & $0(0.003)$ \\
\hline Men & $-0.007(0.024)$ & $-0.033(0.039)$ & $0.03(0.013)$ & $0.001(0.002)$ \\
\hline$p$ for difference across strata & .48 & .33 & .18 & .89 \\
\hline \multicolumn{5}{|l|}{ Race/ethnicity } \\
\hline White & $0.029(0.043)$ & $-0.115(0.078)$ & $0.037(0.023)$ & $-0.004(0.005)$ \\
\hline African-American & $-0.029(0.034)$ & $-0.007(0.055)$ & $0.047(0.023)$ & $-0.005(0.003)$ \\
\hline Hispanic & $-0.019(0.023)$ & $-0.016(0.04)$ & $0.011(0.013)$ & $0.003(0.002)$ \\
\hline$p$ for difference across strata & .89 & .0155 & .0055 & .17 \\
\hline \multicolumn{5}{|l|}{ Socioeconomic position } \\
\hline Lowest & $0.004(0.049)$ & $0.008(0.095)$ & $0.01(0.03)$ & $-0.005(0.005)$ \\
\hline Middle & $-0.008(0.023)$ & $-0.052(0.04)$ & $0.024(0.014)$ & $0.003(0.002)$ \\
\hline Highest & $-0.023(0.035)$ & $0.012(0.053)$ & $0.022(0.023)$ & $-0.003(0.003)$ \\
\hline$p$ for difference across strata & .56 & .89 & .36 & .45 \\
\hline
\end{tabular}

${ }^{a}$ A negative value for the Phase 1 slope and a positive value for the Phase 2 slope indicate slope attenuation of the ascending and descending limbs of the CAR with increases in cynical hostility. A positive value for the intercept indicates a higher waking level with cynical hostility, whereas a positive value for the Phase 3 slope implies that higher cynical hostility levels are associated with slower declines over most of the day following the CAR. For example, in women, each 1-SD increase in cynical distrust is associated with a 0.022 reduction in the P1 (ascending) slope; thus, the PI slope becomes less pronounced as cynical distrust increases; analogously, each SD increase in cynical distrust is associated with a 0.017 increase in the descending P2 slope; i.e., the descending P2 slope becomes flatter as cynical distrust increases.

All models adjust for day of collection, wake-up time, as well as age, race, and sex as covariates or as a stratifying variable. Cynical hostility is modeled as a continuous variable and expressed in SD units. The $p$ values for difference across strata are obtained from nonstratified models including the variable of interest in interaction with cynical hostility and with the specified slope parameter.

$\mathrm{SD}=$ standard deviation; $\mathrm{SE}=$ standard error.

\section{DISCUSSION}

Although the psychophysiological correlates of stress have long been believed to be important mechanisms on the pathway between hostility and coronary heart disease (5), there has been little research on associations between hostility and neuroendocrine correlates of stress. In this cross-sectional analysis of adults aged 45 to 84 years, we found evidence of a small but robust association of cynical hostility with the diurnal rhythm of cortisol. Specifically, after control for multiple confounders by either stratification or regression adjustment, higher levels of cynical hostility were associated with attenuation of the decreasing phase of the CAR. The persistence of this pattern of associations after adjustment for various possible mediators and confounders suggests that cynical hostility has an independent association with this feature of the cortisol curve. Results also suggested that cynical distrust may also be associated with a less steep morning rise, but these differences were not statistically significant.

A substantial literature suggests an association between hostility or its components and various physiological markers of stress. Elevations in hostility are associated with higher plasma catecholamine levels in response to anger-inducing stimuli (42), and it is believed that catecholaminergic systems are involved in the regulation of aggressive behavior (43). Several studies have shown blunted $\beta$-adrenergic receptor function among individuals with high hostility scores $(44-$ 46). Cynical hostility, the hostility measure employed in this study, has recently emerged as a prominent psychosocial correlate of various markers and end points of CVD, including inflammatory markers, obesity, subclinical atherosclerosis (intima-media thickness and coronary calcium), symptom load, and cardiovascular mortality $(24,32,33,47)$, although to our knowledge, there is only one other study (26) linking cynical hostility (as opposed to hostility more generally) to neuroendocrine activity.

To date, only three studies of which we are aware have examined associations of hostility and cortisol levels. One study (25) found that, relative to subjects with low levels of hostility as measured by the entire 50-item Cook-Medley Ho Scale, subjects with high scores on the scale showed significant daytime elevations in urinary cortisol but no waking or evening differences. Smyth et al. (27) found no difference in hostility levels (measured with the Cook-Medley Scale) between overall cortisol profiles characterized as normal, inconsistent, or flat; however, it is not possible to compare their results directly to other studies, as they examined gross characterizations, rather than specific features of the cortisol profile. The single study that is comparable to ours in that it used the cynical hostility subscale (26) showed that high levels of the trait were associated with flattening of cortisol rhythms 
(smaller difference between awakening and evening levels of cortisol), a result that is generally consistent with our results. We add to this work by documenting associations of cynical hostility with cortisol profiles in a large and diverse sample.

The marked daytime elevation observed by Pope and Smith (25) relative to the somewhat weaker results we report may be due to the fact that the full scale includes components of hypersensitivity, aggressive responding, and social avoidance (48), each or all of which may be more strongly related to cortisol output than cynicism. This observation is consistent with the results of several studies that show alterations of cortisol rhythms with feelings of anger or anger expression $(49,50)$. It is possible that cynical hostility, the cognitive component of hostility, relates differently to neuroendocrine activity than the behavioral/experiential component of hostility, such as anger expression and aggressive responding. Differences in the relationship of different components of hostility to coronary heart disease have been noted in other studies (51). One meta-analysis suggested that the effects of hostility on cardiovascular reactivity are demonstrated most clearly in the presence of interpersonal stress situations, such as anger provocation (52). Alternatively, differences in results may reflect differential associations of anger expression and hostility with potential confounders, such as SEP (53). Because the full Cook-Medley Hostility Scale was not administered to MESA participants, we were unable to investigate associations with the full scale or with other hostility subscales in our sample.

Recent investigations have demonstrated that the CAR is a useful index of adrenocortical activity, able to capture subtle changes in hypothalamic-pituitary-adrenal axis secretory activity $(54,55)$. Several investigators have reported stressrelated changes in awakening or morning cortisol levels (5659). Although we found no evidence that hostility was related to wake-up levels or to the morning rise, persons with higher cynical hostility had consistently slower declines after the morning rise. Most studies examining the CAR in various contexts have confined analysis to the rising portion of the CAR $(56,50,59)$. Our findings suggest that the subsequent immediate decline in cortisol level may also be of interest and should be considered along with the rising phase of the CAR. Our modeling technique, which allowed us to characterize and examine different portions of the cortisol rhythm, facilitated detection of these differences.

Although our knowledge of how various features of cortisol rhythms relate to health is still in its infancy, it is significant that cynical hostility, a known correlate of several CVD risk factors and outcomes, seems to relate in a consistent manner with cortisol rhythms in this study. In addition, studies have shown that perturbations of the hypothalamic-pituitaryadrenal axis are linked to metabolic and hemodynamic abnormalities $(12,60,61)$, suggesting a possible pathway through which stress-induced neuroendocrine activity can relate to CVD outcomes.

Very few studies have examined directly cortisol profiles in relation to cardiovascular risk. Coronary calcification-a marker of atherosclerosis of the coronary arteries - has been linked to slower declines in cortisol levels over the course of the day (62). In addition, high awakening levels of salivary cortisol have been found to be associated with lower intimamedia thickness of the carotid arteries, indicating less atherosclerosis (63). Additional studies with other CVD risk factors and biomarkers are needed to determine the biological mechanisms through which cortisol levels may be linked to cardiovascular outcomes.

Our study has limitations. We investigated cynical hostility which, although linked to cardiovascular-related outcomes in prior work, may be a limited measure of the range of hostilityrelated constructs potentially relevant to the cortisol response. Although we had substantially denser cortisol sampling than many observational studies, population-based studies are unable to collect the cortisol samples at the high frequency possible in laboratory studies, and this denser sampling may be necessary to detect subtle features of the cortisol profile. Although the measurement of 3 days is a substantial improvement over prior work (much of which relied on measures over a single day), it is possible that even the 3-day measures are not sufficient to characterize an individual's usual cortisol profile. The paucity of data on predictors of interindividual variability in features of the cortisol curve makes it difficult to draw conclusions regarding the magnitude of the associations we observed, and chance findings cannot be ruled out. In addition, the limited range of the cynical hostility subscale as well as potential error in the measurement of cynical hostility could have biased our results toward the null. These limitations notwithstanding, our findings are consistent with an independent effect of cynical hostility on cortisol. These findings need to be replicated in other samples, and if confirmed, the implications of this for CVD remain to be determined.

We thank the other investigators, the staff, and the participants of the MESA study for their valuable contributions.

\section{REFERENCES}

1. Strike PC, Steptoe A. Psychosocial factors in the development of coronary artery disease. Prog Cardiovasc Dis 2004;46:337-47.

2. Rozanski A, Blumenthal JA, Davidson KW, Saab PG, Kubzansky L. The epidemiology, pathophysiology, and management of psychosocial risk factors in cardiac practice: the emerging field of behavioral cardiology. J Am Coll Cardiol 2005;45:637-51.

3. Brotman DJ, Golden SH, Wittstein IS. The cardiovascular toll of stress. Lancet 2007;370:1089-100.

4. Everson SA, Lewis TT. Psychosocial factors and cardiovascular diseases. Annu Rev Public Health 2005;26:469-500.

5. Smith T, Ruiz J. Psychosocial influences on the development and course of coronary heart disease: current status and implications for research and practice. J Consult Clin Psychol 2002;70:548-68.

6. Lundberg U. Coping with stress: neuroendocrine reactions and implications for health. Noise Health 1999;1:67-74.

7. Hjemdahl P. Stress and the metabolic syndrome: an interesting but enigmatic association. Circulation 2002;106:2634-6.

8. De Kloet ER. Hormones and the Stressed Brain. Ann N Y Acad Sci 2004;1018:1-15.

9. Munck A, Guyre PM, Holbrook NJ. Physiological functions of glucocorticoids in stress and their relation to pharmacological actions. Endocr Rev 1984;5:25-44.

10. Reynolds RM, Walker BR. Human insulin resistance: the role of glucocorticoids. Diabetes Obes Metab 2003;5:5-12.

11. Phillips DIW, Barker DJP, Fall CHD, Seck1 JR, Whorwood CB, Wood 
PJ, Walker BR. Elevated plasma cortisol concentrations: a link between low birth weight and the insulin resistance syndrome? J Clin Endocrinol Metab 1998;83:757-60.

12. Rosmond R, Dallman MF, Bjorntorp P. Stress-related cortisol secretion in men: relationships with abdominal obesity and endocrine, metabolic and hemodynamic abnormalities. J Clin Endocrinol Metab 1998;83: $1853-9$.

13. Whitworth JA, Brown MA, Kelly JJ, Williamson PM. Mechanisms of cortisol-induced hypertension in humans. Steroids 1995;60:76-80.

14. Petrovsky N, McNair P, Harrison LC. Diurnal rhythms of proinflammatory cytokines: regulation by plasma cortisol and therapeutic implications. Cytokine 1998;10:307-12.

15. Kunz-Ebrecht SR, Mohamed-Ali V, Feldman PJ, Kirschbaum C, Steptoe A. Cortisol responses to mild psychological stress are inversely associated with proinflammatory cytokines. Brain Behav Immun 2003;17: 373-83.

16. Yehuda R, Teicher MH, Trestman RL, Levengood RA, Siever LJ. Cortisol regulation in posttraumatic stress disorder and major depression: A chronobiological analysis. Biol Psychiatry 1996;40:79-88.

17. Goodyer IM, Herbert J, Altham PM, Pearson J, Secher SM, Shiers HM. Adrenal secretion during major depression in 8- to 16-year-olds, I Altered diurnal rhythms in salivary cortisol and dehydroepiandrosterone (DHEA) at presentation. Psychol Med 1996;26:245-56.

18. Pruessner M, Hellhammer DH, Pruessner JC, Lupien SJ. Self-reported depressive symptoms and stress levels in healthy young men: associations with the cortisol response to awakening. Psychosom Med 2003;65:92-9.

19. Keller JJ, Flores BB, Gomez RGRG, Solvason HBHB, Kenna HH, Williams GHGH, Schatzberg AFAF. Cortisol circadian rhythm alterations in psychotic major depression. Biol Psychiatry 2006;60: $275-81$.

20. Knox SS, Weidner G, Adelman A, Stoney CM, Ellison RC, for the Investigators of the National Heart LaBIFHS. Hostility and physiological risk in the National Heart, Lung, and Blood Institute Family Heart Study. Arch Intern Med 2004;164:2442-7.

21. Williams JE, Nieto FJ, Sanford CP, Couper DJ, Tyroler HA, Algra A. The association between trait anger and incident stroke risk: the atherosclerosis risk in communities (ARIC) study * Editorial comment: The atherosclerosis risk in communities (ARIC) study. Stroke 2002;33:13-20.

22. Williams RB Jr, Haney TL, Lee KL, Kong YH, Blumenthal JA, Whalen RE. Type A behavior, hostility, and coronary atherosclerosis. Psychosom Med 1980;42:539-49.

23. Pulkki L, Kivimaki M, Elovainio M, Viikari J, Keltikangas-Jarvinen L. Contribution of socioeconomic status to the association between hostility and cardiovascular risk behaviors: a prospective cohort study. Am J Epidemiol 2003;158:736-42.

24. Iribarren C, Sidney S, Bild DE, Liu K, Markovitz JH, Roseman JM, Matthews K. Association of hostility with coronary artery calcification in young adults: the CARDIA study. Coronary artery risk development in young adults. JAMA 2000;283:2546-51.

25. Pope MK, Smith TW. Cortisol excretion in high and low cynically hostile men. Psychosom Med 1991;53:386-92.

26. Sjogren E, Leanderson P, Kristenson M. Diurnal saliva cortisol levels and relations to psychosocial factors in a population sample of middle-aged Swedish men and women. Int J Behav Med 2006;13:193-200.

27. Smyth JM, Ockenfels MC, Gorin AA, Catley D, Porter LS, Kirschbaum $\mathrm{C}$, Hellhammer DH, Stone AA. Individual differences in the diurnal cycle of cortisol. Psychoneuroendocrinology 1997;22:89-105.

28. Bild DE, Bluemke DA, Burke GL, Detrano R, Diez Roux AV, Folsom AR, Greenland P, Jacob DR Jr, Kronmal R, Liu K, Nelson JC, O'Leary D, Saad MF, Shea S, Szklo M, Tracy RP. Multi-ethnic study of atherosclerosis: objectives and design. Am J Epidemiol 2002;156: $871-81$

29. Dressendorfer R, Kirschbaum C, Rohde W, Stahl F, Strasburger C. Synthesis of a cortisol-biotin conjugate and evaluation as a tracer in an immunoassay for salivary cortisol measurement. J Steroid Biochem Mol Biol 1992;43:683-92.

30. Barefoot JC, Dodge KA, Peterson BL, Dahlstrom WG, Williams RB Jr. The Cook-Medley hostility scale: item content and ability to predict survival. Psychosom Med 1989;51:46-57.

31. Barefoot JC, Dahlstrom WG, Williams RB Jr. Hostility, CHD incidence, and total mortality: a 25 -year follow-up study of 255 physicians. Psychosom Med 1983;45:59-63.

32. Julkunen J, Salonen R, Kaplan GA, Chesney MA, Salonen JT. Hostility and the progression of carotid atherosclerosis. Psychosom Med 1994;56 $519-25$.

33. Everson SA, Kauhanen J, Kaplan GA, Goldberg DE, Julkunen J, Tuomilehto J, Salonen JT. Hostility and increased risk of mortality and acute myocardial infarction: the mediating role of behavioral risk factors. Am J Epidemiol 1997;146:142-52.

34. Ranjit N, Diez-Roux AV, Shea S, Cushman M, Seeman T, Jackson S, Ni $\mathrm{H}$. Psychosocial factors and inflammatory markers in the multi-ethnic study of atherosclerosis. Arch Intern Med 2007;167:174-81.

35. Pollitt RA, Daniel M, Kaufman JS, Lynch JW, Salonen JT, Kaplan GA. Mediation and modification of the association between hopelessness, hostility, and progression of carotid atherosclerosis. J Behav Med 2005; 28:53-64.

36. Edwards S, Clow A, Evans P, Hucklebridge F. Exploration of the awakening cortisol response in relation to diurnal cortisol secretory activity. Life Sci 2001;68:2093-103.

37. Ranjit N, Young EA, Raghunathan TE, Kaplan GA. Modeling cortisol rhythms in a population-based study. Psychoneuroendocrinology 2005; 30:615-24.

38. Ranjit N, Young EA, Kaplan GA. Material hardship alters the diurnal rhythm of salivary cortisol. Int J Epidemiol 2005;34:1138-43.

39. Raudenbush SW, Bryk AS. Hierarchical Linear Models: Applications and Data Analysis Methods. Newbury Park, CA: Sage; 2002

40. Singer JD, Willett JB. Applied Longitudinal Data Analysis: Modeling Change and Event Occurrence. New York: Oxford University Press; 2003.

41. Liang K-Y, Zeger SL. Longitudinal data analysis using generalized linear models. Biometrika 1986;73:13-22.

42. Suarez EC, Kuhn CM, Schanberg SM, Williams RB Jr, Zimmermann EA. Neuroendocrine, cardiovascular, and emotional responses of hostile men: the role of interpersonal challenge. Psychosom Med 1998;60: $78-88$.

43. Volavka JAN, Bilder R, Nolan K. Catecholamines and aggression: the role of COMT and MAO polymorphisms. Ann N Y Acad Sci 2004;1036: 393-8.

44. Suarez EC, Shiller AD, Kuhn CM, Schanberg S, Williams RB Jr, Zimmermann EA. The relationship between hostility and beta-adrenergic receptor physiology in healthy young males. Psychosom Med 1997;59: 481-7.

45. Hughes JW, Sherwood A, Blumenthal JA, Suarez EC, Hinderliter AL Hostility, social support, and adrenergic receptor responsiveness among African-American and white men and women. Psychosom Med 2003;65: $582-7$.

46. Sherwood A, Hughes JW, Kuhn C, Hinderliter AL. hostility is related to blunted beta-adrenergic receptor responsiveness among middle-aged women. Psychosom Med 2004;66:507-13.

47. Christensen U, Lund R, Damsgaard MT, Holstein BE, Ditlevsen S, Diderichsen F, Due P, Iversen L, Lynch J. Cynical hostility, socioeconomic position, health behaviors, and symptom load: a cross-sectional analysis in a Danish population-based study. Psychosom Med 2004;66: $572-7$

48. Han K, Weed NC, Calhoun RF, Butcher JN. Psychometric characteristics of the MMPI-2 Cook-Medley hostility scale. J Pers Assess 1995;65: $567-85$.

49. Adam E, Hawkley L, Kudielka B, Cacioppo J. Day-to-day dynamics of experience-cortisol associations in a population-based sample of older adults. Proc Natl Acad Sci 2006;103.

50. Steptoe A, Cropley M, Griffith J, Kirschbaum C. Job strain and anger expression predict early morning elevations in salivary cortisol. Psychosom Med 2000;62:286-92.

51. Whiteman MC, Fowkes FGR, Deary IJ. Hostility and the heart. BMJ 1997;315:379-80.

52. Suls J, Wan CK. The relationship between trait hostility and cardiovascular reactivity: a quantitative review and analysis. Psychophysiology 1993;30:615-26.

53. Haukkala ARI. Socioeconomic differences in measures of hostility. Ann N Y Acad Sci 1999;896:448-50

54. Wust S, Wolf J, Hellhammer DH, Federenko I, Schommer N, Kirschbaum C. The cortisol awakening response-normal values and confounds. Noise Health 2000;2:79-88.

55. Evans P, Hucklebridge F, Clow AFH. The awakening cortisol response: methodological issues and significance. Stress 2004;7:29-37.

56. Schulz P, Kirschbaum C, Prüßner J, Hellhammer D. Increased free 
cortisol secretion after awakening in chronically stressed individuals due to work overload. Stress Med 1998;14:91-7.

57. Pruessner JC, Hellhammer DH, Kirschbaum C. Burnout, perceived stress, and cortisol responses to awakening. Psychosom Med 1999; 61:197-204.

58. Backhaus J, Junghanns K, Hohagen F. Sleep disturbances are correlated with decreased morning awakening salivary cortisol. Psychoneuroendocrinology 2004;29:1181-91.

59. Kunz-Ebrecht SR, Kirschbaum C, Marmot M, Steptoe A. Differences in cortisol awakening response on work days and weekends in women and men from the Whitehall II cohort. Psychoneuroendocrinology 2004;29: $516-28$.
60. Plat L, Leproult R, L'Hermite-Baleriaux M, Fery F, Mockel J, Polonsky KS, Van Cauter E. Metabolic effects of short-term elevations of plasma cortisol are more pronounced in the evening than in the morning. J Clin Endocrinol Metab 1999;84:3082-92.

61. Rosmond R, Bjorntorp P. The hypothalamic-pituitary-adrenal axis activity as a predictor of cardiovascular disease, type 2 diabetes and stroke. J Intern Med 2000;247:188-97.

62. Matthews K, Schwartz JE, Cohen S, Seeman T. Diurnal cortisol decline is related to coronary calcification: CARDIA study. Psychosom Med 2006;68:657-61.

63. Eller NH, Netterstrom B, Hansen AM. Cortisol in urine and saliva: relations to the intima media thickness, IMT. Atherosclerosis 2001;159:175-85. 